\title{
IMPLICACIONES CONSTITUCIONALES DE LAS NUEVAS TECNOLOGÍAS
}

\author{
MARIA PÉREZ-UGENA \\ Profesora Titular de Derecho Constitucional \\ Universidad Rey Juan Carlos
}

ÁLVARO PÉREZ-UGENA

Doctor en Derecho

Master en Derecho de las Telecomunicaciones ICAI-ICADE 


\section{SUMARIO}

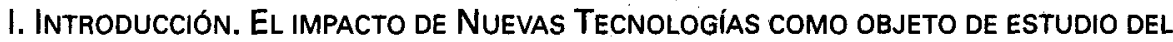
DERECHO CONSTITUCIONAL. II. UNA APROXIMACIÓN A LA SOCIEDAD DE LA INFORMACIÓN. A) Técnico. B) Político. C) Jurídico: i) Convergencia. ii) Globalización. D) La seguridad de la información. III. DERECHO A LA VIDA PRIVADA Y DESARROLLO TECNOLÓGICO. A) Derecho al honor, la intimidad personal y familiar y la propia imagen: i) Derecho al honor. ii) Derecho a la intimidad. iii) Derecho a la propia imagen. B) Derecho al secreto de las comunicaciones. C) Derecho a la protección de datos personales. IV. DERECHOS DE PARTICIPACIÓN. A) Derecho a la comunicación pública libre. B) Derecho de participación politica. C) Otros derechos de participación. V. DERECHOS Y PRINCIPIOS ECONÓMICOS Y SOciales. A) Derechos de carácter económico y social. B) Principios económicos $y$ sociales. 


\title{
IMPLICACIONES CONSTITUCIONALES DE LAS NUEVAS TECNOLOGÍAS
}

POR

\author{
MARIA PÉREZ-UGENA \\ Profesora Titular de Derecho Constitucional \\ Universidad Rey Juan Carlos
}

ÁLVARO PÉREZ-UGENA

Doctor en Derecho

Master en Derecho de las Telecomunicaciones ICAI-ICADE

I. INTRODUCCIÓN. EL IMPACTO DE NUEVAS TECNOLOGÍAS COMO OBJETO DE ESTUDIO DEL DERECHO CONSTITUCIONAL

A lo largo de las dos últimas décadas del pasado siglo se produce una revolución en el ámbito de la comunicación, gracias a la utilización de nuevas tecnologías, que sitúa al siglo $X X I$ ante una nuevo modelo social marcado por la información en un mundo global'1.

1 En Cavero Lataillade, "Presente y futuro de las telecomunicaciones" dentro de la obra colectiva Curso de Derecho de las telecomunicaciones coord. por Merino Merchán y Pérez-Ugena, Dykinson, 2000, págs. 218 y ss., encontramos un listado de sectores a los que los cambios tecnológicos, especialmente, la conjunción de la informática y telemática, podrían afectar. 
Ante las posibilidades que permite la tecnología se tratan de establecer fórmulas de control que protejan los derechos frente a vulneraciones que pudieran tener lugar a través de estos medios. A este efecto surge el Derecho Informático. Sin embargo, la solución no parece estar tanto en potenciar el desarrollo de una rama del Derecho que estudie los aspectos jurídicos de la informática, como en incluir su estudio en las distintas ramas, sin que essto conlleve su desaparición. Asi, la problemática jurídica que pueda plantear la actividad desarrollada a través de medios tecnológicos exige un planteamiento multidisciplinar desde la óptica del Derecho Constitucional, Administrativo, Civil, Penal, Laboral, Procesal, Mercantil, de la Filosofía del Derecho o la Sociología, entre otros.

De hecho, los cambios que suponen el desplazamiento del mundo real al virtual como espacio de desarrollo de una actividad no debían ser, en principio, relevantes. Se delinque, se comercia o se vulneran derechos fundamentales de la misma forma que en un espacio físico, esto es, la actividad, desde un punto de vista conceptual, no varía. Lo distinto es el espacio en el que se desarrolla, el denominado "ciberespacio". ¿Cuáles son las consecuencias de utilización de ese nuevo medio? Quizá, las más evidentes son las que tienen que ver con el efecto denominado "globalización" en el que no se respetan las fronteras tradicionales y se plantean, por tanto, problemas relacionados con el principio de jurisdicción aplicable.

El Derecho Constitucional no puede permanecer al margen de este fenómeno ${ }^{2}$. Al contrario, nos encontramos ante una materia propia de nuestra área de estudio. Entre otras por las siguientes razones:

- En primer lugar, porque es Derecho Común y ha de ser una asignatura que estudie el Derecho Común la que se encargue de analizar cuestiones que tengan contenido jurídico y no encajen en una determinada rama del Derecho ${ }^{3}$.

- En segundo lugar, porque la revolución tecnológica ha supuesto relevantes transformaciones en las relaciones

2 Sobre la relación entre la sociedad de la información y el Derecho Constitucional vid. la introducción a la obra de FERnández Esteban, M. L., Nuevas Tecnologias, Internet y Derechos Fundamentales, Civitas, Madrid, 1998.

3 Fernández Carvajal, R., "Notas sobre el Derecho Constitucional como nuevo "Derecho Común" ", en Anuario de Derecho Constitucional y Parlamenta. rio, núm. 1/1989, págs. 37 y ss. 
sociales y es objeto del Derecho Constitucional el estudio de cuanto afecta a la estructura social misma del Estado.

- En tercer lugar, porque se hacen precisas ciertas reinterpretaciones de cuestiones que forman parte del objeto del Derecho constitucional. Tal es el caso, por ejemplo, de la distribución de competencias a partir del fenómeno de la convergencia, al que haremos referencia.

- En cuarto lugar, porque al tratar sobre las actividades desarrolladas a través de los medios comunicación electrónica entramos de lleno en la regulación de derechos y libertades constitucionales.

Las razones expuestas nos llevan a realizar este trabajo que articulamos de la siguiente forma: Tras una referencia introductoria a la sociedad de la información analizamos los derechos que, desde nuestro punto de vista, se pueden ver afectados de una manera más clara por la aparición y desarrollo de los nuevos medios de comunicación. A estos efectos dividimos en tres grandes grupos los derechos constitucionales (derechos a la vida privada, derechos de participación y, por último, derechos y principios de carácter económico y social).

Finalizamos con una referencia a la seguridad de la información por entender que si no se aplican las medidas necesarias para que la información responda a unos mínimos de seguridad, de poco nos sirven las referencias constitucionales a los derechos previamente analizados.

\section{UNA APROXIMACIÓN A LA SOCIEDAD DE LA INFORMACIÓN}

El desarrollo de nuevos medios de comunicación producto de la conocida como revolución tecnológica, propia de los últimos años, nos lleva a poner adjetivos a la sociedad surgida tras estos cambios tecnológicos. Encontramos, entre los términos acuñados para definir tal fenómeno, el de sociedad de la información ${ }^{4}$, sociedad digital ${ }^{5}$, socie-

4 Éste es el término acuñado por la Unión Europea.

5 Negroponte, N., El mundo digital, Ediciones B, Madrid, 1995; Terceiro, J. B., La sociedad digital. Del homo sapiens al homo digitalis, Alianza Ed., Madrid, 1996. 
dad red ${ }^{6}$, cibersociedad 7 , o sociedad virtual ${ }^{8}$.

Parece básico, a la hora de determinar qué lugar ocupa la tecnología en la sociedad referida, partir de entender que la comunicación es el medio, el motor o instrumento que nos permite utilizar la materia, la información. La técnica nos hace, gracias a la digitalización, dar un uso a la información hasta ahora inimaginable. Ahora bien, la información es la que se convierte en fuente de poder. Nos encontramos ante un bien con características claramente distintas a las propias de un mercado tradicional. La información, tal y como señala Davara, no se agota en su consumo, puede ser utilizada por muchas personas al mismo tiempo, da poder al que la posee y especialmente al que la sabe tratar y utilizar para un fin determinado 9 .

Tratamos a continuación de acercarnos a la sociedad de la información a través de un triple planteamiento, técnico, político y juridico.

A) Desde un punto de vista técnico debemos partir de un proceso de digitalización, de que ha sido objeto la información y que ha puesto las bases necesarias para un uso de la información hasta ahora inconcebible. De otra, realizar la sociedad de la información exige, entre otras condiciones, contar con una infraestructura en la que la anchura de banda garantice la calidad necesaria de la comunicación, la capacidad de interacción esté asegurada, esto es, permita que todo tipo de señales e información sean de doble dirección y la seguridad en el transporte de la información sea suficiente como para permitir transacciones comerciales. La creación de una infraestructura única en la que queden integrados los sistemas de redes, de manera que se

6 CAstells, M., define lo que es la sociedad red. La era de la información. Vol. I: La sociedad red, Alianza Editorial, 1997, págs. 505-514; como un conjunto de nodos interconectados con capacidad de expansión ilimitada entre los que compartan unos mismos códigos. Se van creando distintos tipos de redes a partir de las cuales la sociedad se estructura y la comunicación entre los puntos interconectados de una red fluye sin que exista distancia - tiempo entre ellos. La conexión entre elementos ajenos a una misma red viene marcada por distancias inexistentes en el caso anterior. De esta forma, las relaciones en la sociedad quedan marcadas por la inclusión o exclusión de las redes

7 JoYANES, L., Cibersociedad: los retos sociales ante un nuevo mundo digital, Madrid, McGraw-Hill, 1999; Contreras, F., El Cibermundo. Dialéctica del discurso informático, Alfar, Sevilla, 1987.

8 CONTRERAS, F., op. cit.

9 Davara Rodríguez, M. A., Derecho Informático, Aranzadi, 1993, pág. 13. 
conecten las infraestructuras nacionales de información a una gran red que desarrolle un sistema global de información, es el camino para llegar a implantar la sociedad de la información ${ }^{10}$.

B) En el ámbito político partimos del papel desempeñado por la Unión Europea en la aparición y desarrollo de la sociedad de la información a través de una serie de planes dirigidos a interconectar redes nacionales y crear un espacio común de transmisión de la información ${ }^{11}$.

Sin olvidar que ya desde el año 1979 las reuniones de la Comisión de la Unión Europea hacían referencia a la sociedad de la información y a cómo el progreso tecnológico es fundamental para el crecimiento de Europa, debemos destacar dos documentos básicos en los que se recogen los pasos fundamentales de la política europea de desarrollo de la sociedad de la información; el Libro Blanco de Delors y el Informe Banngenman.

Podemos referir a 1993 el nacimiento de las políticas de desarrollo de la sociedad de la información en Europa con el Libro Blanco de Delors. Bajo el título Crecimiento, competitividad y empleo. Retos $y$ pistas para entrar en el siglo $X X \mid$ se parte de que la inversión en infraestructuras y redes de telecomunicaciones tendrá un impacto trascendental en la sociedad así como que, junto con el medio técnico, es preciso crear un entorno favorable que exige una política de inversiones en diversos sectores, entre los que destaca la educación.

De otra parte, teniendo en cuenta el informe Bangemann, de 1994, Europa y la Sociedad global de la información. Recomendaciones al Consejo de Europa, la Comisión publicó un documento definitivo para la irrupción de Europa en la Sociedad de la información, bajo el título Europa en marcha hacia la Sociedad de la información. Plan de actuación. En la actualidad se desarrolla el programa quinquenal comunitario para establecer la sociedad de la información.

Nuestro país sigue una política de apoyo de entre la que se pueden destacar el Acuerdo del Consejo de Ministros de 9 de abril de 1999,

10 Al respecto vid. NEGROPONTE, op. cit.; TERCEIRO, op. cit., espec. págs. 1926 y $70-76$.

11 Sobre este tema puede verse Pérez Bustamante, Merino Merchán y Castellano Trevilla, Política y Derecho de las telecomunicaciones en la Unión Europea, Dykinson, Madrid, 2000; vid. la obra colectiva Caemades, J., La liberalización de las telecomunicaciones, La Ley, 1999. 
cuyas líneas estratégicas verán la luz en el RD 1282/1999, en el que se determinan objetivos y se crea la Comisión Interministerial de la Sociedad de la Información y de las Nuevas Tecnologías. Además, el RD $557 / 2000$ de reestructuración de Departamentos ministeriales, creará el Ministerio de Ciencia y Tecnología al que hace responsable del impulso de la Sociedad de la Información ${ }^{12}$.

Para la Administración Pública el proceso de transformación de la sociedad de la información resulta especialmente relevante, en cuanto la propia Administración es un sistema complejo de información. En el Libro Blanco del año 2000 se tratan de implementar medidas para la construcción de una Administración ágil y moderna, y se hace especial hincapié en la necesidad de potenciar el uso de los nuevos medios de comunicación, tanto en las relaciones internas como en las que mantiene la Administración con los ciudadanos ${ }^{13}$.

C) Desde un punto de vista jurídico, el desarrollo de la sociedad de la información evidencia la dificultad del Derecho para seguir el ritmo social.

Además hacemos referencia a otros tipos de cuestiones: la convergencia y la globalización.

i) En primer lugar el fenómeno de la convergencia nos exige romper con la idea de que la regulación de medios puede estar referida a éstos como si de departamentos estancos se tratara ${ }^{14}$. La sociedad de la información es convergente. Como consecuencia del desarrollo tecnológico, los sectores que tradicionalmente podían definirse como ámbitos cerrados: audiovisual, telecomunicaciones e informática, pasan a converger gracias a los productos multimedia. Internet,

12 En www.cicyt.es

13 Sobre este tema vid., entre otros, García RuBIO, F., «La teleadministración", en Curso de Derecho de las Telecomunicaciones, coord. MERINO MERCHÁN Y Pérez-Ugena, Dykinson, 2000. págs. 213 a 233. Vid. Pérez-Luño, A. E., Manual de Informática y Derecho, Ariel, El Libro Blanco de la Administración de 4 de febrero de 2000 puede consultarse en www.map.es

14 En el Libro Verde sobre la convergencia de los sectores de telecomunicaciones, medios de comunicación y tecnologías de la información y sobre sus consecuencias para la reglamentación en la perspectiva de la sociedad de la información (COM 97/0236/final) se inicia un extenso debate sobre este fenómeno En particular sobre las posibles implicaciones para la normativa. Vid. FERNÁNDEZ EsTEBAN, op. cit., págs. 75-80. 
embrión de la sociedad de la información, se nos muestra como el paradigma de la convergencia ${ }^{15}$. Pero junto a éste, muchos otros medios o servicios, como la televisión interactiva, vienen a poner de manifiesto la convergencia y a restar validez a esta diferenciación entre sectores.

Pues bien, el fenómeno descrito nos plantea cuestiones jurídicas de distinto orden.

1. De una parte, pierde sentido referir la vulneración de ciertos derechos a determinados medios como la libertad de información a los medios de difusión y otros como el secreto de las comunicaciones a los medios finales, en cuanto esta distinción pierde por efecto de la convergencia sus parámetros de referencia.

2. De otra, en materia de competencias, nos referimos a cómo el régimen de reparto que establece la Constitución entre Estado-Comunidades Autónomas plantea ciertos problemas. Pensemos que el reparto de competencias parte de una distinción entre medios de comunicación social y telecomunicaciones. Distinción que ahora, y por efecto de la convergencia, no es tan clara. De ahí que debamos tener especialmente en cuenta el contenido de ciertas decisiones del Tribunal Constitucional como la STC 278/93 en la que se señala que los títulos competenciales ex artículo 149.1.21 y 149.1.27 se limitan y contrapesan entre sí impidiendo el mutuo vaciamiento de contenidos respectivos, de modo, señala el Tribunal, que todos los aspectos en que prime la naturaleza de un servicio de difusión encuentran acomodo en el punto 1.27 del artículo 149 frente a los aspectos técnicos de la emisión relativos a uso de ondas radioeléctricas o electromagnéticas, que caen en la órbita de la cláusula 1.21.

3. El tercer efecto de la convergencia estaría referido a la necesidad de crear normas que tengan un carácter neutro con respecto a la tecnología, a efectos de regular los nuevos servicios. Esto es, que no impongan la utilización

15 Al respecto vid. Merino Gabeiras y Sotillos SANZ, "Internet: la antecámara de la sociedad de la información", en Curso de Derecho de las telecomunicaciones, coord. Merino Merchán y Pérez-Ugena, Dykinson, 2000, págs. 167-171. 
de un tipo concreto de tecnología, sino que garanticen que un mismo servicio quede regulado de forma equivalente, con independencia del medio a través del cual se preste. $Y$ ello por dos tipos de razones: primera, para evitar los problemas expuestos derivados de la convergencia, y segunda, para que los nuevos servicios que aparezcan en el mercado no hagan surgir lagunas jurídicas, resueltas en muchos casos de manera forzada gracias a la aplicación analógica de la regulación existente, diseñada para un tipo de servicio específico. A estos efectos, sería preciso un enfoque global a la hora de establecer normas, que separe claramente infraestructuras de contenidos.

ii) En otro orden de cuestiones nos referimos a la globalización.

En la sociedad de la información las relaciones jurídico-sociales se desarrollan en un contexto global en el que todo es instantáneo y accesible en el tiempo y en el espacio.

La globalización, que en los últimos tiempos se ha convertido en constante objeto de estudio y referencia, pone de manifiesto una creciente relación entre Estados, un acercamiento entre éstos, con la consecuente tendencia a la eliminación de barreras en todos los ámbitos: financiero, cultural, social, entre otros, que nos conducen a la Aldea Global a que hacía referencia McLuhan, en la que "no existen lugares remotos" ${ }^{16}$. Cierto es sin embargo que no estamos ante un proceso finalizado sino que, muy al contrario, la globalización deja atrás a países "desconectados" respecto de los que aumentan progresivamente las diferencias.

El planteamiento que hacía Jiménez de Parga desde principios de los años 70 cobra plena actualidad frente al desarrollo de la sociedad de la información, al entender que la divísión política únicamente realista es la que diferencia a pueblos industrializados de aquéllos subdesarrollados. Sobre esta base, entiende el citado profesor, se edifican las soluciones políticas ${ }^{17}$.

Pues bien, la creación de la Aldea Global plantea problemas de aplicación del Derecho respecto de aquellas actividades que se reali-

16 MaC LUHAN, Guerra y paz en la aldea global, Martinez Roca, 1971.

17 JIMÉNEZ DE PARGA, M., Los regímenes políticos contemporáneos, Tecnos, Madrid, 1968. 4. ed. 
zan en el ciberespacio ${ }^{18}$. Cuestiones que van desde la necesidad de adaptar el concepto de domicilio, hasta la de establecer criterios para determinar la jurisdicción competente y que en todo caso, por cuanto Internet es un medio no territorial, nos exige la desregulación local o bien nos lleva a aplicar el principio de universalidad ${ }^{19}$.

La cultura digital, señala Jiménez de Parga, «requiere un Derecho ecuménico, en su sentido propio de universal, que se extienda por todo el orbe. El espacio judicial europeo, por ejemplo, que actualmente se nos presenta como un objetivo difícil de alcanzar, será visto por quienes nos sigan -(conjetura este autor) - como algo natural, que ellos reciben en el legado histórico que les corresponde. Lo antinatural en ese futuro (presente) serán las fronteras para lo jurídico» ${ }^{20}$.

Sin embargo, la naturaleza sin fronteras de Internet contrasta con el enfoque localista generalmente adoptado a la hora de tratar de regularlo. Ante la falta de reglas internacionales se vienen aplicando a la Red y a las actividades desarrolladas en un mundo virtual criterios $y$ reglas propios de un mundo real.

De entre las iniciativas que se han llevado a cabo para hacer frente a los problemas que se derivan de la aparición de ese nuevo mundo interconectado destacamos las soluciones que plantea la Directiva 2000/31/CE de 8 de junio de 2000, relativa a determinados aspectos jurídicos de los servicios de la sociedad de la información, en particular del comercio electrónico en el mercado interior. La Directiva prevé la solución extrajudicial de conflictos que quedarían sometidos, de acuerdo con nuestra legislación, a lo dispuesto en la Ley 36/1988, de Arbitraje, en la Ley 26/1984, General para la Defensa de Consumidores y usuarios y a la Ley $7 / 1988$, sobre Condiciones Generales de Contratación.

En desarrollo de esta Directiva se está preparando un Proyecto de Ley sobre los Servicios de la Sociedad de la Información y del dos en Red.

18 El ciberespacio puede definirse como espacio de ordenadores conecta-

19 Vid. Álvarez Cienfuegos, J. M., "Legislación aplicable y jurisdicción competente", en "Jornadas sobre contratación electrónica, privacidad e Internet", Revista Informática de Derecho Informático, año 1999, págs. 143-144.

20 Jiménez dE PARGA, M., Sobre el saber jurídico-político. Un posible enfoque. Discurso de recepción del académico de número Exmo. Sr. D. Manuel Jiménez de Parga, Real Académica de Ciencias Morales y Políticas, Madrid, 2002, pág. 182. 
Comercio Electrónico, la llamada "Ley de Internet", que ha desatado una fuerte polémica en el sector. Las críticas señalan su excesivo intervensionismo así como que podría vulnerar los Derechos del ámbito de la libre comunicación. Nos podemos plantear, asimismo, si no habría sido necesario elevar a rango de Ley Orgánica el contenido de esta Ley por cuanto afecta a Derechos Fundamentales.

\section{D) La seguridad de la información}

La seguridad es pieza clave en el desarrollo de la sociedad de la información de la que depende crear el clima de confianza necesario para que se utilicen los servicios tecnológicos. Por lo mismo, no resultan útiles las formulaciones jurídicas que podamos adoptar para proteger al usuario de un servicio tecnológico en el ejercicio de sus derechos si éstas no vienen acompañadas de las necesarias medidas de seguridad.

Sin seguridad los derechos no tienen validez. Así, las comunicaciones o los datos personales no podrán ser protegidos suficientemente si no es por aplicación del principio de seguridad. Tampoco será posible desarrollar fórmulas de participación política ni plantear la futura implantación de lo que se ha venido en denominar "tecnodemocracia" si no se toman las precauciones necesarias para evitar suplantaciones o modificaciones de resultados. La seguridad se convierte, pues, en presupuesto de cumplimiento de derechos ante la utilización de medios tecnológicos, puesto que al utilizar tales medios para comunicar información, los efectos jurídicos atribuibles a esa información se hacen depender de que ésta se haya tratado de acuerdo con ciertas pautas consideradas suficientemente seguras.

Sin embargo, no resulta sencillo definir la seguridad y su aplicación a la Red. Podemos encontrar, de hecho, distintas acepciones de seguridad en nuestro ámbito de estudio.

Así, hablamos de seguridad en las telecomunicaciones referida a posibles fallos técnicos o a sistemas que pueden considerarse inseguros porque permiten interceptar una comunicación con facilidad.

También la seguridad es una exigencia de los ficheros en que se almacenan datos. La Ley de Protección de Datos y el Reglamento de 
Medidas de Seguridad desarrollan la normativa establecida al efecto en nuestro país 21 .

Otra acepción de la idea de seguridad se relaciona con el control de contenidos. En este sentido que los contenidos sean seguros se traduce, fundamentalmente, en que no incorporen material violento o pornográfico.

Podemos hablar asimismo de la seguridad frente a los actos delictivos en la Red a través de la comisión de delitos informáticos ${ }^{22}$.

La seguridad es, por último, una medida de la que se hace depender la validez de los acuerdos adoptados a través de las comunicaciones electrónicas. En este sentido, la comunicación se entiende segura en los casos en que cumpla ciertos principios: Confidencialidad (la información está sólo disponible para los usuarios); Integridad (la información no se falsea); Accesibilidad (sólo para quienes tienen derecho); Autenticidad (asegura el destino y origen de la información; remite quien dice ser y no otra persona) e Imposibilidad de rechazo (impide alegar el NO envío o recepción) ${ }^{23}$.

De entre las técnicas que se utilizan para asegurar la información, la criptografía ocupa un papel primordial. Se trata de una fórmula que permite cifrar la información, esto es, convierte un texto plano en un texto ininteligible, de manera que para ser descifrado precisa de la llave correspondiente ${ }^{24}$.

21 Martínez Sánchez, M. M., «Medidas de seguridad de las bases de datos. Desarrollo reglamentarion, en XX Conferencia internacional de autoridades de protección de datos, 1998, Madrid, Agencia de Protección de Datos 1999, págs. $210-$ 225; Peso Navarro, E., "La seguridad de la información en la Ley de Protección de Datos de Carácter Personal», en XIII Encuentros sobre Informática y Derecho, Universidad Pontificia Comillas, Madrid, 2000, págs. 41-58.

22 Existe una amplia bibliografía sobre el delito informático. Vid., por ejemplo, Corcoy BIDAsolo, M., Protección penal del sabotaje informático, La Ley, 1990; Jover PAdRó, J., «El código penal de la informática», en $X$ Encuentros sobre Informática y Derecho 1996-1997, ICADE, Aranzadi, 1997, Madrid, págs. 349-370.

23 Ribagorda GaRnaCHO, A., "Seguridad en las transacciones electrónicas II", en XIII Encuentros sobre informática y Derecho 1999/2000, ICADE, Aranzadi, Madrid, págs. 115-120; Barriuso RuIz, C., La Contratación electrónica, Dykinson, 1998; RECALDE CASTELLS, A., "Comercio y contratación electrónica", en Jornadas sobre contratación electrónica, privacidad e Internet, UNED, Mérida, 1999. págs. 39-88.

24 Vid., entre otros, MARTínez NADAL, A., Comercio electrónico, firma digital y autoridades de certificación, Civitas, Madrid, 1999. 
Nuestra legislación sobre Telecomunicaciones permite el uso de técnicas criptográficas, si bien contempla también la posible obligación de notificar los procedimientos de cifrado a determinados órganos, lo que de hecho abre la posibilidad de creación de depósitos de llaves.

En este marco hacemos referencia a la firma electrónica regulada recientemente en desarrollo de la Directiva 1999/93 sobre esta materia como medio de identificar al autor de un documento. Si bien hay distintas formas de firmar electrónicamente un documento, la firma digital, como subproducto de firma electrónica, aumenta el grado de fiabilidad de documentos surgidos a través de medios de comunicación electrónica.

La firma digital utiliza técnicas criptográficas, de acuerdo con formulas de criptografía asimétrica, y si es avanzada (categoría que le viene dada por el cumplimiento de ciertos requisitos en el RDL 14/99 sobre firma electrónica), se equipara con la firma manuscrita y tiene valor probatorio ${ }^{25}$. Uno de los requisitos precisos para que la firma sea calificada como avanzada es que esté avalada por un prestador de servicios de certificación de acuerdo con la normativa reguladora de esta materia 26 .

25 SANCHIS CRespo, La prueba por soporte informático, Tirant Lo Blanch, 1999, págs. 47-62; Prieto GutiérRez, J. M., «Problemática y expectativas en torno al documento electrónico probatorio: valor probatorio", en Jornadas sobre contratación electrónica, privacidad e Internet, UNED, Mérida, 1999, págs. 437-460; BARRIUso RuIz, C., pág. 29, señala que la jurisprudencia ha venido otorgando validez al documento electrónico por vía analógica siempre que sea auténtico y haya sido obtenido lícitamente. (STC 29/11/84; STS 30/11/81, 5/2/88, 15/2/90 y 30/11/92). PALADELLA SALORD, C., "El documento electrónico como prueba. La reforma del Código Civilı, en Revista Electrónica de Derecho Informático, núm. 26, septiembre 2000.

26 Cuervo Álvarez, F., «La firma digital y entidades de certificación", en Jornadas sobre contratación electrónica, privacidad e Internet, UNED, Mérida, 1999, págs. 235-276. En la misma obra colectiva vid. las aportaciones de MOLINA MATEOS, J. M., "Firma electrónica y fe pública extrajudicial», págs. 419-435, y BoLAs AtFonso, J., "Seguridad en la contratación por Internet: Firma electrónica y fe pública», págs. 89-105.

El Gobierno español ha aprobado las siguiente normas en este sentido: Real Decreto 1290/1999, de 23 de julio, por el que se desarrolla el artículo 81 de la Ley 66/1997; Ley 55/1999, de 29 de diciembre, de Medidas Fiscales, Administrativas y del Orden Social. En su artículo 51 se modifica el artículo 81 de la Ley 66/1997, de 30 de diciembre, de Medidas Fiscales, administrativas y del Orden Social, adicionando dos nuevos apartados en los que se amplía la prestación de los servicios de la FNMT-RCM, como Entidad de Certificación a los Órganos Jurisdiccionales.En desarrollo de lo dispuesto en el citado RD se acuerdan una serie de convenios con la Fábrica Nacional de Moneda y Timbre para la prestación de los servicios de segu- 
Éstos serían, en grandes líneas, los rasgos que caracterizan nuestro sistema tecnológico desde la perspectiva de la seguridad. Vemos cómo la seguridad se convierte en presupuesto de cumplimiento de derechos y mecanismo mediante el que se otorga valor con efectos jurídicos de carácter vinculante a las actividades desarrolladas en la Red.

En los apartados a que nos referimos a continuación pondremos en relación los derechos y la tecnología. Sin embargo, el objeto de estudio no se ha centrado en un concreto derecho o un grupo de derechos. Al contrario, trata sobre distintos derechos pertenecientes a ámbitos diferentes en los que el hilo conductor, el punto de conexión, viene dado por las singularidades que percibimos en tales derechos en cuanto entran en contacto con el mundo de las nuevas tecnologías. A estos efectos, distinguimos entre derechos de la vida privada, derechos del ámbito de la participación y, por último, derechos y principios de carácter económico y social.

\section{DERECHO A LA VIDA PRIVADA Y DESARROLLO TECNOLÓGICO}

Las nuevas tecnologías facilitan la vulneración de derechos fundamentales relacionados con el ámbito de la vida privada por cuanto, desde un punto de vista técnico, los medios al alcance de segmentos de la población cada vez más amplios se hacen más potentes y sofisticados. A lo anterior debemos sumar el que la información esté adquiriendo un enorme valor, que puede llevar a una paulatina restricción del ámbito de derechos del ámbito del artículo $18 \mathrm{CE}$. Especialmente el derecho tricéfalo que garantiza el artículo 18.1, honor, intimidad y propia imagen, al que se atribuye un carácter flexible y que se hace depender en gran parte de las ideas que prevalezcan en cada momento en la sociedad, puede verse constreñido ante la imposición de criterios económicos ${ }^{27}$.

ridad en las transacciones teletemáticas. Así con: Ministerio de Administraciones Públicas, Agencia Estatal de Administración Tributaria, Ministerio de Industria y Energía, el Ministerio de la Presidencia, varias CC.AA., Diputaciones Provinciales y Ayuntamientos.

27 Sobre la naturaleza de estos derechos existe una amplia bibliografía. Podemos señalar, ConCEPCIÓn Rodríguez, J. L., Honor, Intimidad e Imagen, Bosch, Barcelona, 1996; Crevillén SÁnCHez, C., Derechos de la Personalidad, Honor, Intimi- 
El secreto a las comunicaciones se constituye en garantía de protección de la vida privada frente a la sociedad tecnológica y viene a ocupar un papel determinante en el propio desarrollo de la sociedad de la información. Del mismo modo, el mandato constitucional del articulo 18.4, al conectar intimidad e informática, es el apoyo constitucional del derecho de creación doctrinal de autodeterminación informativa o control de los datos, que es también instrumento fundamental de protección de la vida privada frente a la utilización de nuevas tecnologías.

La legislación de desarrollo tutela penalmente la protección de los derechos a la vida privada en las telecomunicaciones y las comunicaciones electrónicas a través de la protección del secreto (el Código Penal, en su artículo 197.1, mediante una enumeración enunciativa que deja abierta la posibilidad de que surjan nuevos medios $u$ objetos tecnológicos) así como la protección de datos en ficheros 0 soportes informáticos, electrónicos o telemáticos (el Código Penal en el segundo párrafo del artículo citado). Del mismo modo, la Ley General de Telecomunicaciones (11/1998) incluye entre sus disposiciones las relativas al secreto de las comunicaciones (artículo 49), a la protección de datos personales (artículo 50), las interceptaciones de las telecomunicaciones por servicios técnicos (artículo 51) y el cifrado, al objeto de garantizar técnicamente los derechos fundamentales constitucionalmente reconocidos.

Vemos a continuación separadamente los derechos del ámbito de la vida privada que de forma más clara pueden quedar afectos por el uso de las nuevas tecnologías.

\section{A) Derechos al honor, a la intimidad personal y familiar $y$ a la propia imagen}

i) El derecho al honor ${ }^{28}$ entendido como derecho al respeto del buen nombre o fama que deriva de su dignidad y que evita desmere-

dad Personal y Familiar y Propia Imagen en la Jurisprudencia. Doctrina y Jurisprudencia, Actualidad Editorial, Madrid, 1995; HerRero TeJedor, F., Honor, Intimidad y Propia Imagen, Colex, Madrid, 1990.

28 Sobre el derecho al honor existe una amplia bibliografía. Vid. BALAgUeR CALleJón, M. L., El derecho fundamental al honor, Marcial Pons, Madrid, 1992; Cossío CASTELAR, M., Derecho al honor: técnicas de protección y límites, Tirant lo Blanch, Valencia, 1993; Estrada Alonso, E., El derecho al honor en la Ley Orgánica 1/1982, 
cimiento en la consideración ajena (SSTC 232/1992, 170/94) puede ser vulnerado a través de medios tecnológicos, de la misma forma que se puede vulnerar sin publicidad alguna. Así, la injuria y calumnia se pueden dar sin publicidad, tal y como determina el Código Penal. Sin embargo, tenemos en cuenta que, de una parte, la publicidad se toma en consideración a la hora de aplicar una pena superior, y de otra, que el derecho al honor es cambiante y referido a realidades intangibles, cuyo núcleo deberán determinar los órganos judiciales. Pues bien, reconocer que se ha vulnerado este derecho resulta más sencillo en los supuestos en que hay divulgación. Se señalan como formas típicas de divulgación en las que hay publicidad, la imprenta, la radiodifusión y otros semejantes.

A través de la utilización del servicio de telecomunicación referido a la telefonía vocal difícilmente podemos hablar de divulgación, excepción hecha de algunos supuestos como, por ejemplo, aquellos en que a través de una conversación telefónica se participe en una tertulia radiofónica o similar. Sin embargo, los medios de comunicación electrónica, como Internet, resultan ideales para la realización de actos vulneradores del derecho al honor ${ }^{29}$.

Relacionado con las limitaciones informáticas a que alude el artículo 18.4 apenas encontramos referencias al derecho al honor. La Exposición de Motivos de la hoy derogada LORTAD se refería a este derecho, al señalar que el conocimiento de datos podría dibujar un determinado perfil de una persona o configurar una determinada reputación o fama que es, señala la ley, expresión del honor. Pues bien, el tratamiento de datos gracias al desarrollo de sistemas que permiten almacenar cada vez mayor número de datos en espacios menores y a costes reducidos pone información antes vedada al alcance de todos y supone un riesgo al facilitar que se vulnere el derecho al honor.

De otra parte, y respecto de los medios de comunicación electrónica, tengamos en cuenta que en nuestros días una gran parte de ciudadanos tienen acceso a éstos y pueden volcar en ellos cualquier

de 5 de mayo, Civitas, Madrid, 1988; Madrid, 1994. Del mismo autor: La configuración constitucional del derecho a la intimidad, Tecnos, Madrid, 1995. Sobre el derecho al honor como límite del derecho a la información vid. ORTEGA GUTIÉRREZ, D., Derecho a la información versus derecho al honor, Centro de Estudios Constitucionales, Madrid, 1991.

29 Herrero Tejedor, F., "La protección del honor y de la intimidad en el ámbito de las telecomunicaciones», en Régimen de telecomunicaciones, coord. Merino Merchán, F., y Pérez-Ugena, M., Tecnos, 1998, págs. 136-151. 
información. El hecho de que el alcance de los medios de comunicación social, radio, televisión y prensa, quedara reservado a ciertos grupos, en cierta medida facilitaba el control de contenidos ilícitos o, al menos, encontrábamos unos cauces más claros a la hora de exigir responsabilidad.

El ejercicio de la libre expresión se encuentra con posibilidades hasta ahora inimaginables, aunque, al mismo tiempo, también nos encontramos ante un medio que facilita el que se vulnere el derecho al honor y en el que su defensa se hace mucho más compleja, tal y como hemos podido ver en la aparición de páginas en Internet en las que aparecían listados, entre otros el de las víctimas contra la asociación de la tortura o las del defensor del paciente.

\section{ii) Derecho a la intimidad personal y familiar}

El derecho a la intimidad implica ${ }^{30}$ la posibilidad de excluir a terceros del conocimiento de cuestiones que afectan al ámbito de lo privado o personal. Es asimismo un derecho flexible, cuya valoración depende, de la misma forma que el derecho al honor, de factores sociales, a los que se atribuye un carácter relativo que le hacen depender en gran medida de las ideas que prevalezcan en cada momento en la sociedad (STC 171/1990, de 12 de noviembre) ${ }^{31}$.

Aun cuando no sea objeto de este trabajo entrar en a definir el derecho a la intimidad, tarea, de otra parte, compleja y que suscita tal variedad de problemas que suele ser objeto de estudios que forman parte de monografías, no podemos olvidar que la referencia "tecnológica" en el artículo 18.4 de la Constitución pasa por tratar la intimidad como límite y nos impone una reflexión obligada en este sentido.

30 Sobre el derecho a la intimidad se han publicado numerosas obrar. Pueden verse, entre otras: ESPINAR VICENTE, J. M., Estudios sobre el derecho a la intimidad, Tecnos, Madrid, 1992; Fariñas MATONI, L. M., El Derecho a la intimidad, Trivium, Madrid, 1983; García San Miguel Rodríguez-Arango, L., Reflexiones sobre el derecho a la intimidad, Madrid, 1992; HerRero TEJEDOR, F., La intimidad como derecho fundamental, Madrid, Colex, 1998; MARTínez PIsón CAVERo, J., El Derecho a la intimidad en la jurisprudencia constitucional, Civitas, Madrid, 1993; ReBOllo DelGADO, L., El derecho fundamental a la intimidad, Madrid, Dykinson, 2000; RuIz MigUEL, C., El derecho a la protección de la vida privada en la jurisprudencia del Tribunal Europeo de Derechos Humanos, Civitas.

31 En este sentido vid. Preámbulo de la Ley Orgánica de Protección Civil del Derecho al Honor, la Intimidad Personal y Familiar y la Propia Imagen. 
En derecho alemán, el libre desarrollo de la personalidad engloba el derecho a la intimidad, de acuerdo con la concepción que refleja el artículo 1.2 de la Ley Fundamental Alemana, en cuanto aquél, se entiende como un derecho general de libertad. La intimidad, respecto del libre desarrollo de la personalidad, actúa como un derecho especial, suplementario y subsidiario. En España, el Tribunal Constitucional sigue la misma doctrina y el derecho a la intimidad aparece como un fondo del que se separan derechos concretos ${ }^{32}$. De forma que el derecho a la intimidad se entiende relacionado con el contenido del artículo 10.1 de la Constitución, y derivado de la propia dignidad de la persona humana y su necesidad de desarrollo personal (STC 53/1985, de 11 de abril).

En principio, la intimidad se entiende referida a la autonomía personal. Es un ámbito o reducto en el que se veda que otros penetren (STC 73/1982, de 2 de diciembre). Su protección conlleva la creación de un ámbito exento de injerencias externas y reservado para la vida privada, entendida como la capacidad de la persona de autorregular su conducta y conectada con esta idea de reserva de un espacio propio, un reducto vedado a terceros en el que se eviten injerencias externas, de forma que ciertos hechos queden resguardados de la curiosidad y el conocimiento de terceros. Es el derecho a estar solo, a no ser molestado, a guardar reserva sobre la propia vida privada.

En cualquier caso está claro que el tratamiento del derecho a la intimidad con la aplicación de las nuevas tecnologías se torna más complejo que en épocas anteriores, en cuanto la capacidad de vulneración de los derechos es muy superior a la que permitían las técnicas desarrolladas hace pocos años ${ }^{33}$. En nuestros días, los avances tecnológicos ha obligado a extender la protección de la vida privada más allá del aseguramiento del domicilio como espacio físico en el que normalmente se desenvuelve la intimidad y del respeto a la correspondencia (STC 110/1984). De ahí que la afectación de lo íntimo precise cada vez una protección más clara.

La conexión entre intimidad e informática plantea una serie de cuestiones que no pueden resolverse acudiendo a un análisis de la Ley

32 RodRígUEz RUIz, B., El secreto a las comunicaciones: tecnologia e intimidad, McGraw Hill, págs. 23-26.

33 Puede verse sobre esta cuestión Álvarez Cienfuegos Suárez, J. M., La defensa de la intimidad de los ciudadanos y la tecnología informática, Aranzadi, Pamplona, 1999. 
de Protección de datos. La problemática jurídica que surge a partir de esta relación parte de un objeto mucho más amplio y pasa por el necesario estudio de ciertas materias que exigen, en primer lugar, aclarar el concepto de "intimidad" al referirnos a la protección de la vida privada y señalar, si las hay, las diferencias entre ambos. $Y$ es precisa esta aclaración, principalmente, porque el término intimidad se utiliza de forma recurrente a la hora de imponer límites a la utilización de las tecnologías para la protección de la vida privada.

Si bien generalmente hablamos de intimidad para englobar los problemas más relevantes en el ámbito privado relacionados con las nuevas tecnologías, debemos plantearnos hasta qué punto es correcto hacer extensiva la utilización de este término a cualquier supuesto que relacione las dos cuestiones señaladas.

El término intimidad hace referencia a lo espiritual, lo interno, lo íntimo. La vida privada no ha de tener esa connotación íntima, sino que se trata de proteger lo que se pretende que quede fuera de control de terceros. Es un término, por tanto, más amplio. Si bien ambos se utilizan de forma indistinta con cierta frecuencia, desde un punto de vista estricto, no son realmente sinónimos, desde el momento en que la intimidad afecta a lo personal sin que la vida privada tenga porqué hacerlo. De ahí que el objeto de protección varíe si protegemos la vida privada o bien la intimidad. Valga como ejemplo la referencia al control de datos. A estos efectos, la distinción entre ambos conceptos es clara. Asi, si bien en la Constitución, el artículo 18.4 CE se refiere a limitación de la informática frente a la intimidad, la Ley Orgánica Reguladora del Tratamiento Automatizado de Datos de Carácter Personal (LORTAD) - hoy derogada- hace referencia en su Exposición de Motivos, a esta diferencia en los términos siguientes:

"Notesé que se habla de privacidad y no de la intimidad. Aqué* lla es más amplia que ésta, pues en tanto la intimidad protege la esfera en que se desarrollan las facetas más singularmente reservadas de la vida de la persona - el domicilio donde realiza su vida cotidiana, las comunicaciones en las que expresa sus sentimientos, por ejemplo-, la privacidad constituye un conjunto más amplio, más global de facetas de su personalidad que, aisladamente consideradas pueden carecer de significación pero que, coherentemente enlazadas entre sí arrojan como precipitado un retrato de la personalidad del individuo que éste tiene derecho a mantener reservado. Y si la intimidad, en sentido estricto, está suficientemente protegida por las previsiones de los tres primeros párrafos del artículo 18 de la Constitución y por las leyes que los desarrollan, la privacidad puede resultar menoscabada por la utilización de las tecnologías informáticas de tan reciente desarrollo". 
Estamos pues ante conceptos más amplios que podríamos considerar protegidos gracias al reconocimiento de un derecho a la vida privada, pero no, según lo expuesto, a la intimidad.

Los derechos de la vida privada, siguiendo con el tema del tratamiento de datos, y por tanto su protección, no se refieren, de esta forma, de manera exclusiva a informaciones referidas a los aspectos "íntimos" del sujeto, que con carácter general coinciden con los denominados "datos sensibles" sino que afectan a cualquier información del titular de tales datos.

Se podrían, también, suponer dos sentidos distintos de la intimidad. Intimidad entendida en un sentido estricto y referida al ámbito de lo personal, que correspondería con el concepto clásico de intimidad, e intimidad entendida en su sentido más amplio, como equivalente al término "privacy» ${ }^{34}$. Esta última concepción de intimidad nos sitúa en una mejor posición a la hora de enfrentarnos a los problemas que surgen como consecuencia de los cambios sociales impuestos por las tecnologías. Lo que nos permite utilizar el término intimidad sin reconducirlo al contenido específico del artículo $18.1 \mathrm{y}$ poder entender que la utilización de datos personales puedan vulnerar la intimidad aun cuando no afecten a la esfera de lo estrictamente íntimo o personal sin precisar de la utilización de otros términos o conceptos.

\section{iii) Derecho a la propia imagen}

El derecho a la propia imagen ${ }^{35}$, por último, junto con los derechos al honor y la intimidad, forma parte de los bienes de la personalidad que pertenecen al ámbito de la vida privada. Puede definirse como el derecho que tiene cada uno a evitar la captación de su imagen sin su consentimiento, así como de su reproducción. Garantiza el ámbito de libertad de una persona respecto de sus atributos más característicos, propios e inmediatos como son la imagen física, la voz o el nombre, cualidades definitorias del ser propio y atribuidas como pose-

34 El término anglosajón "privacy" no tiene traducción a nuestra lengua. Se suele traducir como "privacidad" aunque éste no está aceptado en la lengua española.

35 Sobre el derecho a la propia imagen puede verse, entre otros, ALEGRE MARTínez, M. A., El derecho a la propia imagen, Tecnos, Madrid, 1997; AZURMENDI AdarRaga, A., El derecho a la propia imagen, Civitas, Madrid, 1997. 
sión inherente e irreductible a toda persona (STC 117/1994, de 25 de abril).

La protección de la propia imagen, tal y como ha señalado el Tribunal Constitucional, reviste singular importancia frente al creciente desarrollo de los medios y procedimientos de captación, divulgación y difusión de la misma y de datos y circunstancias pertenecientes a la intimidad que garantiza este precepto (STC 170/1987).

Se refiere a rasgos físicos, externos y que por tanto no pueden reproducirse, en principio, a través del servicio telefónico si nos referimos a la telefonía vocal básica. Ahora bien, por vía telefónica podrían, igualmente, transmitirse imágenes, bien a través de sistemas de telecomunicación que incorporen esta opción o bien a través de Internet.

\section{B) Derecho al secreto a las comunicaciones}

El Derecho al secreto de las comunicaciones alcanza en nuestros días enorme relevancia. Si el motor de esa nueva sociedad, la materia prima sobre la que se sostiene, es la información, crear cauces de comunicación seguros para transmitir tal información es una de las bases necesarias para su desarrollo.

Nuestra Constitución, al garantizar el derecho al secreto de las comunicaciones, "y en especial de las postales, telegráficas y telefónicas, salvo resolución judicial", incorpora un derecho autónomo, aun cuando guarde una estrecha relación con el derecho a la intimidad. De manera que la vulneración de un derecho no implica la del otro, tal y como ha puesto de manifiesto el TC, sino que el secreto tiene un carácter formal, independiente del contenido material del derecho a la intimidad y puede ser opuesto sólo frente a terceras personas ajenas a la comunicación (STC 114/1984) ${ }^{36}$.

36 Respecto del régimen del secreto de las comunicaciones véase, de entre la bibliografía existente sobre la materia: JIMÉNEZ DE PARGA, M., "La defensa constitucional del secreto de las comunicacionesn, en Régimen de las telecomunicaciones, coord. Merino Merchán y Pérez-Ugena, Tecnos, 1998, págs. 121-135; JiméNEZ CAMPO, J., "La garantía constitucional del secreto de las comunicaciones", Revista Española de Derecho Constitucional, aAño 7, núm. 20, mayo-junio 87, págs. 35-55; MaRTín Morales, R., El régimen constitucional del secreto de las comunicaciones, Civitas, 1995; Rodríguez RuIz, B., El secreto de las comunicaciones: tecnologia e intimidad, McGraw-Hill, 1998. 
El derecho al secreto hay que aplicarlo en nuestros días a un concepto de comunicación que tiene un objeto más amplio que el que podiamos utilizar en 1978. Hoy la comunicación alcanza una mayor presencia en la sociedad, es instrumento necesario para realizar actividades que años atrás se desarrollaban de manera distinta, utiliza medios o canales de distribución antes inexistentes, es más rápida y es interactiva, por lo que, convierte al emisor en receptor y viceversa.

Lo anterior, en principio, no debería plantear grandes problemas, en cuanto la referencia al secreto que encontramos en la Constitución es abierta. La tutela de las comunicaciones es, siguiendo a Jiménez Campo, numerus apertus, lo que permite que nuevas formas de comunicación, no previstas en la Constitución puedan formar parte del ámbito de protección del Derecho ${ }^{37}$.

De otra parte, también como consecuencia del desarrollo tecnológico, la convergencia de las tecnologías nos lleva a plantearnos la confusión a que puede dar lugar el que la regulación de una actividad parta de criterios técnicos, de acuerdo con la tecnología que presta el servicio de que se trata ${ }^{38}$.

En esta línea tenemos en cuenta que el secreto de las comunicaciones no tiene sentido en todos los casos de transmisión de información. Se hace preciso distinguir a estos efectos los supuestos en que el derecho al secreto de las comunicaciones está presente, de forma especial en los casos en que nos encontramos ante los denominados servicios multimedia.

El derecho al secreto de las comunicaciones tiene su razón de ser en los casos en que hablamos de telecomunicaciones, y no en cuanto éstas entran en contacto con medios de comunicación social. Quiere esto decir, que respecto de los denominados canales abiertos, cuyo fin o destino es la difusión, no tiene sentido hablar de secreto. Tal es el caso de la radio o televisión. Cosa distinta es la protección del derecho a la intimidad referido al tratamiento de datos cuando se utilicen medios tales como la televisión interactiva, pero es un tema que no entraría en el ámbito del secreto sino en el de la protección de datos.

37 JimÉnEz CAMPO, "La garantía...", op. cit., pág. 54.

38 En el Libro Verde sobre la convergencia de los sectores de telecomunicaciones, medios de comunicación y tecnologías de la información y sobre sus consecuencias para la reglamentación en la perspectiva de la sociedad de la información (COM 97/0236/final) se inicia un extenso debate sobre este fenómeno. En particular sobre las posibles implicaciones para la normativa. 
El desarrollo de productos convergentes resta valor a esta clásica distinción entre soportes y nos hace acudir a los contenidos para determinar la aplicabilidad del régimen del secreto. Así, en Internet habrá que estar a la utilización del medio, esto es, si se presta un servicio típico de telecomunicación, por ejemplo, utilización de correo electrónico, el secreto está presente, y no lo está, si se trata de un servicio propio de los medios de comunicación social, como puede ser la prensa digital.

En el ámbito de las telecomunicaciones ${ }^{39}$, la interceptación, aun cuando debe ser considerada como una de las injerencias más graves en la vida privada de las personas (STS 18-6-92, "Caso Naseiro"), constituye una interferencia de las autoridades bastante frecuente, mediante escuchas judiciales como forma de lucha contra las formas modernas de criminalidad organizada.

Ciertas cuestiones relacionadas con el régimen del secreto en telecomunicaciones se han resuelto a través de la jurisprudencia del TC. Asi, el que se entienda vulnerado el derecho por el solo conocimiento de las horas de llamada o números a que se llama, independientemente del contenido de la conversación, las facultades que se reconocen a los que formen parte de una conversación, para grabarla o utilizar amplificadores, aun sin conocimiento del interlocutor (STC 114/84) o el hecho de que haga extensible a la telefonía móvil la regulación del antiguo Código Penal, parece que prevista únicamente para telefonía vocal básica (STC 34/96), ponen de manifiesto el deseo de interpretar el derecho a que nos referimos de la forma más amplia posible.

La Ley General de Telecomunicaciones, por su parte, exige a las operadoras de telecomunicaciones garantizar el secreto a través de las medidas técnicas necesarias (artículo 49). Además de que "la comunicación a la policia, a los efectos de una investigación penal, de los datos registrados por el servicio de comunicaciones sobre destino u origen de las llamadas y su duración" son una injerencia a los efectos del artículo 8 del CEDH de acuerdo con la jurisprudencia del TEDH señala en su sentencia 2-8-84 (caso Malone).

39 Las telecomunicaciones pueden definirse, de acuerdo con lo dispuesto en el Anexo a la Ley General de Telecomunicaciones, como "Toda transmisión, emisión o recepción de signos, señales, escritos, imágenes, sonidos o informaciones de cualquier naturaleza por hilo, radio-electricidad, medios ópticos u otros sistemas electromagnéticos". 
En el ámbito de los nuevos servicios de comunicación electrónica debemos destacar el desarrollo del correo electrónico que, frente al correo postal, es más rápido, económico y eficaz, además de que permite el intercambio de ficheros y posibilita la reproducción de la información un número indefinido de veces. Frente a tales ventajas se hace necesario regular un mínimo garantizador que proteja la información que fluye a través de este nuevo sistema de comunicación. Especialmente, porque el hecho de que la interceptación del correo sea sencilla, a no ser que se utilicen fórmulas de protección adecuadas, y la posibilidad de utilizar programas que tengan por objeto el control simultáneo de grupos numerosos de personas, de manera que el programa sea capaz de captar la utilización de ciertas palabras como claves permite, sin duda, una mayor capacidad de control así como crear perfiles con gran facilidad.

Frente a esas posibilidades de control, los usuarios de los nuevos medios de comunicación pueden proteger su información mediante procedimientos criptográficos. La criptografía permite cifrar los mensajes de forma que no es posible el descifrado sin la correspondiente llave.

En el ámbito de la empresa, el tema del derecho al secreto en el correo electrónico y su utilización como medio de despido ha despertado en los últimos tiempos cierta polémica. Se mueve entre el Derecho del empresario al ejercicio de su poder de dirección y control de cumplimiento de las obligaciones laborales y la aplicación del derecho al secreto como derecho fundamental que, en concreto, al utilizar esta forma de comunicación nos lleva a preguntarnos si estamos ante un bien de la empresa o si el correo es personalizado ${ }^{40}$.

Hacemos por ultimo referencia al Chat. El hecho de que su forma ordinaria de utilización sea anónima, y podamos conceptuarlo, en principio, como medio con carácter de canal cerrado, aun cuando al mismo tiempo le sea atribuible una capacidad de repercusión impropia de los medios finales, nos llevado a sugerir el anonimato como derecho del cibernauta frente a lo que más bien parece un límite pro-

40 García, G., "El acceso al correo electrónico por parte del empresario», www.derin.unineto.edu 13/03/00. AGENCIA DE PROTECCIÓN DE DATOS, Memoria anual 1999, Madrid, 2000, págs. 248-249 y 275-277. Vid. ST TSJ Cataluña de 14-11-2000 por despido improcedente que trajo su causa en el envio de mensajes electrónicos, por entender que se han utilizado medios informáticos con que cuenta la empresa "en gran número de ocasiones» para fines ajenos a los laborales. 
pio de la libertad de expresión que viene a proteger derechos de terceros.

El derecho al derecho al secreto de las comunicaciones no tiene, al igual que cualquier otro derecho constitucional, un carácter absoluto. El propio artículo $18.3 \mathrm{CE}$, al reconocer el secreto, incluye la salvedad de la resolución judicial que se fundamenta en un principio de seguridad.

En el ámbito de las telecomunicaciones, el Consejo de Europa ha establecido los requisitos necesarios para la interceptación. En el orden interno, la Ley de Enjuiciamiento Criminal ha venido a condensar en su artículo 579 los aspectos procesales relativos a este derecho fundamental con la reforma por LO 4/1988. Y la jurisprudencia, de la que es ejemplo la STS, Sala 2, de 20 de enero de 1998, señala los requisitos de las intervenciones. Además de tratarse de una medida prevista legalmente y con una necesidad para la protección de intereses colectivos o generales, debe acordarse para descubrir un delito, tener carácter excepcional, proporcional, y deberá realizarse con un control judicial efectivo.

Aun así, se plantean problemas, especialmente respecto a la validez de los actos que intercepten comunicaciones realizados antes de 1988 , por cuanto existe un vacío legal entre los diez años que median desde la aprobación de la CE hasta que se modifica la LECrim. Si bien la jurisprudencia venía utilizando la vía analógica integradora y aplicando criterios de proporcionalidad, el TEDH ha condenado a España por violación del artículo 8 del CEDH al permitir que se intercepten comunicaciones sin ley al efecto en el caso Valenzuela-Contreras versus España en 1998.

De otra parte, se nos plantea un tema referido de manera específica a los nuevos medios de comunicación en cuanto no permiten el control judicial último previsto en la Constitución si previamente no se ha hecho depósito de la llave capaz de descifrar la información. De ahí que pudiera estar justificada la creación de depósitos que vienen a evitar los espacios vedados a la autoridad judicial. Lo que, de otra parte, exigiría establecer las medidas necesarias para la seguridad del propio depósito de llaves.

Lo anterior nos lleva a la dialéctica: seguridad - libertad. La seguridad plasmada en la creación de depósitos de llaves, o la limitación al uso de técnicas criptográficas. $Y$ la libertad que negaria las acciones anteriores como forma de asegurar el derecho al secreto, y por tan- 
to la libertad de comunicación, al no hacerlas depender de las medidas de seguridad de tales bancos de llaves.

\section{C) Derecho a la protección de datos personales}

El coste nulo de almacenar datos, la mayor capacidad de almacenamiento de la información en los sistemas informáticos, el desarrollo de redes de telecomunicaciones que permiten el acceso y transmisión de información en plazos cada vez más breves, son algunas de las posibilidades que ofrece el desarrollo tecnológico y que permite un sin fin de opciones de utilización de la información. Tales opciones vienen a otorgar a la información un enorme valor. De ahí que el Derecho a la autodeterminación o control sobre los datos tenga, cada día, más importancia.

Se trata de un derecho de creación doctrinal que encuentra su fundamento constitucional en el mandato al legislador contenido en el artículo 18.4 de la CE, en el que se trata de limitar "el uso de la informática para garantizar el honor y la intimidad personal y familiar de los ciudadanos y el ejercicio de sus derechos» ${ }^{41}$. Es, pues, tal y como ha reconocido el TC a partir de la STC 254/1993, una garantía constitucional, como forma de respuesta a una nueva forma de amenaza a la dignidad y a los derechos de la persona, es un instituto de garantía de otros derechos, fundamentalmente el honor y la intimidad, pero también es un instituto que es, en sí mismo, un derecho autónomo, distinto al derecho a la intimidad y que implica capacidad de control sobre los datos. Este derecho garantiza la libertad frente a las potenciales agresiones a la dignidad y la libertad de las personas ante el uso ilegítimo del tratamiento mecanizado de datos ${ }^{42}$.

41 Al reconocimiento de este derecho se refiere LuCAS MURILLo, P., en su obra El derecho a la autodeterminación informativa, Tecnos, Madrid, 1990. Vid. también, del mismo autor, Informática y protección de datos personales. Estudios sobre la LO 5/1992 de Regulación Automatizada de los Datos de Carácter Personal, CEC, Madrid, 1993; Heredero Higueras, M., La Ley Orgánica 5/ 1992, de regulación del tratamiento automatizado de datos de carácter personal, Tecnos, Madrid, 1996.

42 De entre los comentarios a la STC 254/1993 vid. VILLAVERDE MENÉnDEZ, "Protección de datos personales, derecho a estar informado y autodeterminación informática, a propósito de la STC 254/1993", Revista Española de Derecho Constitucional, mayo-agosto 1994, págs. 189-223. 
Llama especialmente la atención el hecho de que la reciente Carta de Derechos Fundamentales de la Unión Europea desarrolle de forma bastante detallada el derecho a la protección de datos de carácter personal ${ }^{43}$. Tras consagrar este derecho y determinar que los datos se han de tratar de modo legal, para fines concretos y sobre la base del consentimiento de la persona afectada o en virtud de otro fundamento legítimo previsto por la ley, reconoce los derechos de acceso y rectificación y prevé la figura de la autoridad de control. De esta forma la Unión Europea no sólo reconoce el derecho de autodeterminación informática sino que además deja expresa constancia de la existencia de un habeas data que se manifiesta a través de instrumentos específicos al servicio de este Derecho. Tales previsiones reflejan la toma de conciencia de la necesaria protección de la vida privada ante las cada vez superiores posibilidades de uso de la información.

Recordemos que, tal y como se hacía constar en la hoy derogada LORTAD, el desarrollo tecnológico permite salvar las dificultades que imponen el tiempo y el espacio en el acceso a los datos. El tiempo procuraba con su transcurso que se evanescieran los recuerdos e imposibilitaba la configuración de una historia lineal e ininterrumpida de las personas y la distancia dificultaba el conocimiento de hechos que se produjeran lejos del lugar en que nos halláramos. Hoy, tiempo y distancia no son, gracias a las nuevas tecnologías, salvaguarda de la vida privada.

Las enormes posibilidades actuales en el tratamiento de los datos justifican que el Derecho, teniendo en cuenta las conexiones que permiten los nuevos medios, convierta en objeto de protección cualquier dato, esto es, cualquier información referida a personas físicas identificadas o identificables. Lo anterior no obsta, sin embargo, para que podamos diferenciar entre distintos tipos de datos estableciendo, tal y como la hace la ley, una categoría tripartita de acuerdo con la importancia que se atribuya al dato de que se trate.

Nuestro régimen de protección de datos, desde la aprobación de la citada LORTAD, responde a una regulación legal general, que se adscribe a las previsiones del Convenio 108 del Consejo de Europa para la protección de las personas con respecto al tratamiento de datos automatizados de carácter personal. Ello sin perjuicio del desarrollo

43 Artículo 8 de la Carta de Derechos Fundamentales de la Unión Europea de diciembre de 2000 (DOCE C364, de 18-12-2000). 
normativo específico de determinadas materias, así como de los códigos de conducta existentes.

La aprobación de la Directiva 95/46, por la que se regula la protección de las personas físicas en lo que respecta al tratamiento de datos personales y la libre circulación de estos datos, impone ciertas modificaciones al régimen existente ${ }^{44}$. Si bien mantiene los preceptos impugnados por el Defensor del Pueblo ante el Tribunal Constitucional por vulneración de Derechos Fundamentales desde los ficheros públicos. Lo que ha provocado la declaración de inconstitucionalidad, en STC 292/2000, de varios preceptos de la reciente Ley ${ }^{45}$.

La sentencia citada declara inconstitucional las excepciones recogidas en la Ley al ejercicio de los derechos de información, acceso, rectificación y cancelación por parte de ficheros de titularidad pública. (artículos 24.1 y 15 y 16.1$)^{46}$.

Quizá sea el régimen de transferencias internacionales el que provoque dificultades de protección más claras. En el ámbito europeo

44 DO L 281 de 23.11.1995, pág. 31; Respecto de la Directiva se han publicado varias obras. Entre ellas: Heredero Higueras, M., La Directiva Comunitaria de Protección de Datos de Carácter Personal, Ed. Aranzadi, Pamplona, 1997; Bueno ARús, F., "Acerca de las transposición de la Directiva comunitaria sobre el tratamiento de datos", págs. 21-32.

45 Pleno STC 292/2000, de 30 de noviembre. Recurso de inconstitucionalidad 1463/2000. Promovido por e Defensor del Pueblo respecto de los artículos 21.1 y 24.1 y 2 de la LO 15/1999, de 13 de diciembre, de Protección de Datos Personales. Vulneración del derecho fundamental a la protección de datos personales. Nulidad de varios preceptos de la LO (BOE núm 4, Suplemento, de 4 de enero de 2001). Al respecto puede verse: ABAD AMORós, M. R., "El recurso de Inconstitucionalidad del Defensor del Pueblo contra la LO 15/22, de Protección de Datos de Carácter Personal», Revista Electrónica de Derecho Informático, núm. 28, noviembre de 2000, http://publicaciones.derecho.org/redi

46 Respecto a la nueva Ley de Protección de Datos puede verse PUENTE Escobar, A., "Reflexiones sobre la nueva Ley Orgánica de Protección de Datos de Carácter Personal», Boletín de legislación, núm. 130, 2000, págs. 6 a 10; Davara Rodríguez, M. A., "La nueva Ley Orgánica de Protección de Datos de Carácter Personal", XIII Encuentros sobre Informática y Derecho, Universidad Pontificia Comillas, Madrid, 2000, págs. 15-30; en la misma obra colectiva, Bueno ARús, F., «Acerca de las transposición de la directiva comunitaria sobre el tratamiento de datos", págs. 21-32; García Ontoso, R. M., "Comentarios a la nueva Ley de Protección de Datos de Carácter Personal, de 13 de diciembre de 1999", en XIII Encuentros sobre Informática y Derecho, Universidad Pontificia Comillas, Madrid, 2000, págs. 31-40; Fernández López, J. M., "La nueva Ley de Protección de Datos de Carácter Personal de 13 de diciembre de 1999. Su porqué y sus principales novedades", en Actualidad Informática Aranzadi, núm. 34, enero de 2000, págs. 2-17. 
se aprueba la citada directiva 95/46. La entrada en vigor de esta Directiva provoca la modificación del régimen de protección de datos y la entrada en vigor de la nueva LO 15/9947.

La Directiva distingue entre protección «equivalente», referida a los países miembros, y "adecuada" para terceros países. Es respecto de las transferencias a estos terceros países ajenos al régimen de la Directiva europea de los que se plantean mayores problemas. De hecho, EE.UU. no cuenta en principio con un régimen de protección de datos equivalente y ha obligado, por intereses económicos de relación comercial con estos países, a crear acuerdos que han recibido la denominación de acuerdos de puerto seguro, sobre la base de declaraciones de las propias compañías americanas ${ }^{48}$. Se trata así de buscar una actitud flexible en Europa que evite efectos devastadores para la posición de las empresas en el mercado mundial ${ }^{49}$.

En el ámbito de las telecomunicaciones, el régimen de protección de datos, si bien sigue los principios generales establecidos en la

47 Estadella YUSTE, O., La protección de la intimidad frente a la protección internacional de datos personales, Tecnos, Madrid, 1995; FERNÁNDEZ LóPEZ, J. M., "Flujo internacional de datos", en Jornadas sobre contratación electrónica, privacidad e Internet, UNED, Mérida, 1999, págs. 189-203; SEABRa LOPES, J., "Transmisiones internacionales y métodos para reforzar la cooperación internacional», en XX Conferencia Internacional de autoridades de protección de datos 1998, Agencia de Protección de Datos, 1999, págs. 199-209; Reidenderg, J., "Transferencias internacionales de datos y métodos para reforzar la cooperación internacional", en. XX Conferencia Internacional de autoridades de protección de datos 1998, Agencia de Protección de Datos, 1999, págs. 165-186, espec. 169-170.

48 En este sentido puede verse Diaz ARIAS, R., "Transferencia de datos personales. ¿Llegarán nuestros datos a buen puerto?, sobre el reciente acuerdo sobre protección de datos alcanzado entre Estados Unidos y la Unión European, Revista Electrónica de Derecho Informático, núm. 23, junio 2000, en http://publicaciones.derecho.org/redi. Se hace referencia en este artículo al acuerdo de 14 de marzo de $\mathbf{2 0 0 0}$ por el que la Unión Europea y Estados Unidos sientan las bases para permitir que los datos personales recogidos en los Estados Miembros puedan ser transferidos a organizaciones establecidas en Estados Unidos. Se própugna una solución basada en la combinación de legislación, regulación y, sobre todo, autocontrol empresarial. El acuerdo parte de aceptar el flujo de datos hacia compañias que acepten un conjunto de principios y prácticas definidos por el Departamento de Comercio. El sistema safe harbor parte de otorgar validez a la autodeclaración de la propia compañía, que se compromete a cumplir los principios definidos en el documento.

49 ManganelLI, C., "Internet", en XX Conferencia Internacional de Autoridades de Protección de Datos 1998, Agencia de Protección de Datos, 1999, págs. 121-137.En la misma obra colectiva, vid. SEABRA LOPES, "Trasmisiones Internacionales y métodos para la cooperación Internacional", págs. 199-209. 
Directiva 95/46 de protección de datos a que nos hemos referido, por contar con ciertas peculiaridades exige un tratamiento específico. A estos efectos es preciso tener en cuenta la Directiva 97/66 relativa al tratamiento de los datos personales y la protección de la intimidad en el sector de las telecomunicaciones. En la citada norma, cuya transposición curiosamente se ha llevado a cabo en nuestro país a través de una norma reglamentaria, el Reglamento del Servicio Universal (RD 1736/98, de 31 de julio, por el que desarrolla la Ley General de Telecomunicaciones), se presta atención a cuestiones como el destino de los datos obtenidos a través del tráfico o facturación, el tratamiento de datos en las guías de telecomunicaciones, etc. ${ }^{50}$

Sin embargo, el desarrollo de nuevos servicios exige determinar el régimen aplicable a los datos tratados y que, en principio, ha de ser distinto al de los servicios de telecomunicación. Así plantea problemas especificos lo referido a servicios que utilizan datos de localización geográfica, puesto que podrian implicar un mayor control sobre el individuo. Estos datos, al tiempo que otorgan mayor efectividad a los equipos de urgencia son útiles para colaborar con la seguridad, pueden suponer un peligro para la vida privada de los usuarios de móviles que quedarian en posición de vigilancia permanente. Lo mismo ocurre con las guías electrónicas. El alcance mundial de estas guías, la posibilidad de realizar búsquedas inversas o el hecho de que a esta información se pueda acompañar otra, como un mapa de localización, puede exigir un tratamiento distinto al de los datos de las guías impresas. En aplicación de nuevas tecnologías al ámbito de la televisión se plantean también problemas de protección de datos, especialmente en lo que se refiere a transferencias internacionales de datos ${ }^{51}$.

50 Respecto al régimen de protección de datos en este ámbito vid. Davara, M. A., La protección de datos en el sector de las telecomunicaciones, Madrid, 2000. En XII Encuentros sobre Informática y Derecho, Universidad Pontificia Comillas, Madrid, 1999, vid. CorripIo GIL-Delgado y Fernández AlLeR, C., "La protección de datos personales en las autopistas de la información", págs. 114 y ss., y en los XIII Encuentros sobre Informática y Derecho, ANCOS Franco, H., «El tratamiento automatizado de datos personales en el ámbito de las telecomunicaciones. Comentario a la consulta 1/1999 de la Fiscalía General del Estadon, págs. 69-80; PÉrez-UgeNA, M., "Protección de datos en el ámbito de las telecomunicaciones", en Curso de Derecho de las Telecomunicaciones, coord. Merino Merchán, J. F., y Pérez-Ugena, M., Dykinson, 2000.

51 "Breve apunte sobre la televisión digital en Estados Unidos", publicado en la web especializada sobre televisión digital interactiva www. tvdi.net, 31-12002, "Artículos de opinión". 
Dadas las facilidades de control que permiten algunos servicios como los mencionados es preciso reforzar el régimen de control y de manera especial garantizar que el consentimiento de su titular se haya prestado expresamente.

A estos efectos en la actualidad se prevé respecto de la citada norma un proceso de modificación para incluir en su ámbito de protección otras formas de comunicación electrónica, de acuerdo con el ya citado principio de neutralidad tecnológica 52.

En Internet, establecer un régimen de protección de datos presenta muchas complicaciones debido a la gran facilidad de tratar información que ofrece la Red, así como a la dificultad de controlar y regular el tratamiento ${ }^{53}$. Y esto, fundamentalmente por dos motivos. Primero, la estructura de Internet es abierta. Se trata de un medio universal basado en el principio de indeterminación geográfica, en el que coexisten muchos intermediarios con acceso a los datos, y en el que cuestiones, como la distancia y situación, resultan irrelevantes a la hora de procesar información. Y segundo, porque se trata de un medio interactivo. Es el propio usuario quien entrega datos. Sin embargo, el usuario puede ceder en su derecho a controlar los datos al hacer entrega de los mismos, a veces de forma consciente y otras de manera inconsciente ${ }^{54}$.

De entre los primeros supuestos hacemos referencia como forma típica que permite obtener información a las llamadas cookies. Se trata de unas fichas que recogen información para identificar a un

52 En este sentido se expresa la propuesta de la Directiva relativa al tratamiento de los datos personales y a la protección de la intimidad en el sector de las comunicaciones electrónicas COM 2000(385) final 12/7/2000.

53 MARTínez SÁNCHEZ, M. M., "Tecnología informática y confidencialidad de los datos personales", en Escuela Judicial. Consejo General del Poder Judicial. Cuadernos de Derecho Judicial, 1997, págs. 151 a 193.

54 Sobre las cookies y otras agresiones a la intimidad vid. MuÑOZ MACHADo, La regulación de la Red. Poder y Derecho en Internet, Taurus, 2000; Ramos SUÁREZ, F., "¿Es legal el uso de las cookies?", en Revista Electrónica de Derecho Informático, núm. 1, agosto 1998; CASACUBERTA, D., "La privacidad en los nuevos medios electrónicos. Aspectos éticos y sociales", en Revista Electrónica de Derecho Informático, núm. 99, de 11 de junio, www. derecho.org/redi; HeSS ARAYA, C., "Derecho a la privacidad y cookies", en Revista Electrónica de Derecho Informático, núm. 24, julio 2000. Sobre esta problemática vid. el documento de trabajo sobre le tratamiento de datos personales en Internet aprobado por el Grupo de trabajo el 23 de febrero de 1999 en AgEnCIA DE PRoteCCIÓN DE DATOS, Memoria 1999, Agencia de Protección de Datos, 2000, págs. 338 y ss. 
usuario que visita un sitio web a efectos de futuras visitas, con lo que es posible establecer preferencias de los usuarios y crear perfiles. En otros casos el titular de la información la cede de forma consciente pero con una finalidad distinta de la prevista. Así, por ejemplo, al inscribirse en una lista de distribución.

Ante las dificultades que plantea la situación descrita, la Unión Europea, a través del grupo de trabajo especializado en materia de protección de datos, dicta una serie de Recomendaciones, bien dirigidas a los usuarios en que advierte sobre los beneficios de utilizar la red de forma anónima (Rec. 3/97), o bien dirigidas a los proveedores de productos informáticos, en las que les instan a evitar el diseño de programas con la función "tratamiento de datos por defecto" (Rec. 1/99).

Han surgido asimismo instrumentos técnicos al efecto ante la dificultad de regular normativamente el régimen de protección de datos en Internet. Las plataformas P3P tienen su origen en EE.UU. y parten de la filosofía de acuerdo entre sitio web y usuario a la hora de establecer preferencias en el navegador de conformidad con el nivel de protección que el usuario pretenda mantener. De esta forma si las prácticas del sitio se ajustan a los deseos del usuario el acceso es directo. Si no, se preguntará al usuario sobre si quiere o no acceder ${ }^{55}$.

Por último, la puesta en práctica de códigos éticos vislumbra una posible solución a través de la autorregulación. Se trata de una posibilidad prevista en la normativa española y europea sobre protección de datos, que en Estados Unidos es la fórmula principal a efectos de protección de datos. Se centra en acuerdos que tienen el carácter de códigos de buena práctica profesional, con los que se trata de que las empresas que participen activamente en la Red se comprometan a seguir ciertos principios de protección de datos.

Podemos destacar el Código Ético que presenta la Federación Española de Comercio Electrónico y Marketing Directo, al que se han sumado empresas de distintos sectores y es una muestra del sistema de autorregulación. Estas empresas adquieren, por el hecho de estar inscritas en el código ético, el derecho a usar un sello de garantía de

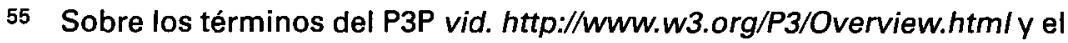
análisis jurídico del World Wide Web Consortiun (W3C) en http://www.w3.org/TR/P3P. analysis 
protección de datos que actúa como aviso a los visitantes del sitio web de que los datos alli depositados cumplen con los requisitos que exige la ley de protección de datos ${ }^{56}$.

El problema que se plantea es que la garantía para el consumidor viene dada por la prohibición de utilizar el sello, así que la sanción se produce cuando se han sufrido daños, en algunos casos irreparables. Además la capacidad de sancionar con que cuenta la asociación se reduce a realizar advertencias o amonestaciones y retirar, ya sea temporal o definitivamente, el sello de garantía.

Las soluciones apuntan, finalmente, a estrechar la coordinación internacional. Si bien, al menos de momento, parece impensable crear una regulación general de Internet, la pretensión es llegar a un consenso mundial creciente sobre la base de acuerdos multilaterales respecto de cuestiones especificas en Internet.

\section{DERECHOS DE PARTICIPACIÓN}

\section{A) Derecho a la comunicación pública libre}

Los derechos de participación alcanzan en la Red una nueva dimensión. Internet puede considerarse como un instrumento al servicio de la libertad de expresión. De ahí que los Gobiernos de ciertos países que tratan de poner trabas a la libertad ideológica limiten el acceso a los contenidos de Internet conscientes del riesgo que este medio de comunicación conlleva para el mantenimiento de regímenes que precisan la desinformación de sus ciudadanos ${ }^{57}$.

Pero en nuestro entorno tampoco la libertad de expresión responde a un concepto absoluto. Los límites que en nuestra Constitución determina el propio artículo 20 encuentran en el ámbito de Internet claras dificultades para imponerse porque la regulación de este medio, como advertimos, es muy compleja por las características atribuibles a un sistema de comunicación mundial y no territorial ${ }^{58}$.

56 Sobre la finalidad de esta asociación y su política de protección de datos vid. www.aece.org

57 Álvarez Cienfuegos, J. M., "Legislación aplicable y jurisdicción competente", op. cit. págs. 162-175.

58 Vid. MUÑOz MACHADO, S., La regulación de la red. Poder y Derecho e Internet, Taurus, 2000. 
La regulación del medio es compleja. Si cada jurisdicción pretende regular las actividades desarrolladas en Internet sería posible sancionar el contenido de una determinada página con sede en un país en que si cumple con la legislación. Incluso el que vierte un contenido en la Red puede verse obligado a cumplir prescripciones contrarias entre sí para ser conforme con los principios de los distintos Estados.

Entre otras opciones destaca como posible solución prohibir el acceso a ciudadanos de una determinada nacionalidad respecto de contenidos contrarios a la normativa del país de origen de tales ciudadanos, en supuestos en que el servidor que ofrezca tal información tenga su sede en un país en el que tal información no se constituya en objeto de una actividad ilícita. Sin embargo ante esta solución se imponen problemas técnicos como pueden ser los que dificultan la identificación del origen.

Las dificultades señaladas no han impedido que la libertad de expresión en Internet trata de regularse. En Europa las líneas de acción han ido dirigidas, tras la aprobación del Libro Verde sobre protección de menores y de dignidad humana en los nuevos servicios audiovisuales y de la información, a cubrir los siguientes frentes: Creación de una red europea de líneas directas que permite notificar los contenidos ilícitos, desarrollo de mecanismos de filtración y clasificación de contenidos, fomento de sensibilización y una mayor cooperación internacional.

\section{B) Derecho de participación política}

Si la democracia es un sistema de diálogos entre gobernante y gobernados las nuevas tecnologías se ponen al servicio de la democracia en cuanto permiten introducir mejoras en ese diálogo ${ }^{59}$.

En el ámbito de la participación política la aplicación de nuevas tecnologías puede permitir una presencia más activa del ciudadano en la toma de decisiones. Tanto en lo que se refiere al ejercicio del derecho de participación directa como a la participación a través de representantes. Sin embargo debemos tener en cuenta una premisa previa

59 JimÉnEZ de PARgA, M., introduce una crítica al papel actual de las instituciones representativas y a la situación de desfase en que se encuentran a partir del fenómeno de televisación de los poderes. En La ilusión política ¿Hay que reinventar la democracia? Alianza, 1993. 
de ejercicio del derecho de participación a través de medios tecnológicos. Para que la participación sea efectiva y pueda valorarse es precisa una implantación tecnológica suficiente. En el caso contrario los resultados de la participación serán meros reflejos de las tendencias de un segmento social concreto, sin que puedan tener validez como orientaciones de la generalidad de la población.

Lo anterior pretende hacer valer en el ámbito de la participación el principio de igualdad real que consagra el artículo 9.2 de la CE. Lo contrario supondría una vuelta a sistemas oligárquicos. Esto nos lleva a plantearnos en qué condiciones entendemos que se ha dado cumplimiento al principio de igualdad. El problema no parece estar tanto en el acceso físico al medio, que podría entenderse cubierto con la creación de centros tecnológicos en cada pequeña localidad, como en que la generalidad de la población esté familiarizada con la utilización del medio. Lo que enlaza directamente con una de las piezas claves de desarrollo de la sociedad de la información: la educación.

Dentro de los parámetros señalados, en lo que se refiere a la democracia directa, está claro que si bien no como forma ordinaria de gobierno, por cuanto las instituciones realizan una función de integración y consenso necesaria, sí que las nuevas tecnologías pueden servir para potenciar el acceso al ciudadano en la vida política. Las nuevas tecnologías han comenzado ya a aplicarse en el ámbito de las instituciones de representación. El Gobierno ha creado el proyecto «Agora" como primer prototipo de democracia electrónica aplicado en La Rioja ${ }^{60}$.

En el ámbito parlamentario, el Senado de nuestro país ha creado un parlamento virtual como herramienta de participación de las actividades que desarrolle la Cámara. Y la Comisión Internet se ha constituido en foro público en el que cualquier ciudadano puede expresar su opinión 61 .

De otra parte, en lo que se refiere al ejercicio del derecho de sufragio, la inclusión del voto electrónico puede coadyuvar a la reducción de costes y permitir la realización de consultas de forma mucho más ágil. Para hacer factible esta opción es preciso implantar sistemas de seguridad que eviten cualquier manipulación que pueda alterar los

60 Puede verse en www.larioja.com

61 Sobre la creación de la comisión vid. BOCG, serie l, núm. 10, 16-5-2000. 
resultados, y que, además, logre hacer valer el principio de que el voto es secreto62.

Las nuevas tecnologias pueden ser, por último, un instrumento de control de la acción política en manos de los ciudadanos. La información a que se tiene acceso en la red, por cuanto es interactiva, puede tener como objeto temas puntuales referidos a la actividad de un partido y que pueden constituir interés especifico de ciertos ciudadanos o grupos de poder.

\section{C) Otros derechos de participación}

El derecho de participación política a que nos hemos referido parte de una derecho previo: el derecho a la información. La democracia se alimenta de la información, de ahí que resulte falsificada en los regímenes en que bien no hay información, bien está manipulada.

El Derecho de información en su vertiente pasiva ha sido tradicionalmente referido a los medios de comunicación social. La aparición de nuevas tecnologías se traduce en un aumento de las fuentes de información. Si bien es cierto que, en el caso de Internet, nos podemos encontrar con tal exceso de fuentes que los árboles no nos dejen ver el bosque. Además no toda la información que ofrece Internet es útil. Muy al contrario la mayor parte de páginas de Internet pueden clasificarse como documentos basura y muchos caminos en la Red no llevan a ningún sitio. Frente a tales inconvenientes, la verdadera aportación de las nuevas tecnologías al derecho de la información es la interactividad, gracias a la que el receptor tiene capacidad para decidir respecto de la información a que quiere tener acceso.

Es preciso, asimismo, hacer referencia al Derecho de petición, por cuanto en su nueva regulación reconoce que las nuevas tecnologías serán el cauce natural de su ejercicio.

62 Respecto del voto electrónico puede encontrarse la información recogida en www.kriptopolis.com/criptograma/ctg.htm/. De entre las publicaciones que encontramos en la Red podemos destacar: RuBı, R., "La campaña electoral a través de la Red", en www.derin.uninet.edu, I Congreso Internacional de Derecho e Informática en Internet. VELARDE KOECHLIN, C., "Hacia una democracia digital: propuestas de aplicación», en I Congreso Internacional de Derecho e Informática en Internet, www.derin. ínineto.edu. Este artículo se ha publicado también en REDI (Revista Electrónica de Derecho Informático) núm. 28, de noviembre de 2000, www.derecho.org/redi 
También facilita la aplicación de nuevas tecnologías el ejercicio del derecho de asociación, no sólo como medio de conexión entre asociados, sino también porque ayuda a dotar de mayores dimensiones a la actividad que se desarrolle en la Red.

En el Derecho de jurisdicción, por fin, las aportaciones de la informatización de la administración de justicia, qué duda cabe, colaboran para obtener cuotas más altas de cumplimiento de este derecho. No olvidemos, además, que los principios generales de funcionamiento de la Administración como los de eficacia o racionalidad, entre otros, rigen igualmente el buen funcionamiento de la Administración de Justicia 63 .

\section{DERECHOS Y PRINCIPIOS ECONÓMICOS Y SOCIALES}

\section{A) Derechos de carácter económico y social}

El punto de partida de la problemática que presentan estos derechos en relación con la tecnología es el principio de servicio universal.

Podemos observar una clara tendencia en Europa de marcado carácter liberal plasmada en la privatización de ciertos servicios que formaba parte del sector público. La liberalización de las telecomunicaciones, que en EE.UU. tiene lugar con el fin del monopolio de ATT y la aparición de las llamadas baby bells, en Europa se desarrolla gracias a un complejo proceso que encuentra su origen en Reino Unido con la aparición de un segundo operador en 1984 y que será continuado desde instancias europeas a partir del libro verde sobre liberalización de las telecomunicaciones en 1987.

Sin embargo, esta actitud liberalizadora no aleja definitivamente al Estado de una cierta intervención social al objeto de hacer frente a las disfunciones del propio sistema. Esta intervención estatal justifica el reconocimiento del principio de servicio universal gracias al que quedan cubiertas las necesidades básicas de los ciudadanos en

63 Sobre los efectos de la informática en la Administración de Justicia vid. Pérez luño, op. cit., págs. 92 y ss. También vid. Rayón Ballesteros, C., "La informatización de la Administración de Justicia», en XII Encuentros sobre informática $y$ derecho 1998-1999, ICADE, Madrid, 2000, págs. 333-348. En la misma obra colectiva, Álvaro Bermejo, C., "Un paso adelante en la modernización de la justicia: el centro de documentación judicial», págs. 323-331. 
materia de prestación de servicios de telecomunicaciones, al margen de los intereses puramente económicos de las empresas. El principio de servicio universal viene, de esta forma, a sustituir las garantías que ofrecía al ciudadano la concepción de las telecomunicaciones entendidas como servicio público en la etapa en que el servicio se prestaba en régimen de monopolio64.

Los principios básicos del servicio universal son universalidad, acceso para todos a un precio asequible, igualdad, con independencia de la ubicación geográfica, y continuidad, durante toda la vida. De acuerdo con tales principios el servicio universal permite el acceso a un conjunto mínimo de servicios definidos de una calidad determinada. $Y$ supone la prestación de tales servicios a todos los usuarios, independientemente de su situación geográfica y a un precio asequible.

En nuestro país, desde que la empresa Telefónica de España deja de ser un monopolio y los servicios que presta entran en régimen de competencia con otras compañías ${ }^{65}$, se asume el principio del servi-

64 Sobre el servicio universal vid., entre otros: QUADRA SALCEDO, T., "Telecomunicaciones y Derecho público", en Derecho de las Telecomunicaciones, coord. Cremades, J., La Ley, Madrid, 1997, págs. 131 y ss.; VILlar URIBARRI, J. M., "Pautas para una nueva regulación de las telecomunicaciones en España", en Derecho de las Telecomunicaciones, coord. CremadeS, J., La Ley, Madrid, 1997, págs. 112 y ss.; SÁNCHez Rodríguez, A. J., "Servicio universal ante la reforma de las telecomunicaciones", Noticias Jurídicas, núm. 18, junio 1997, págs.10 y ss. ARIÑo OrTIz, G., "Servicio público y servicio universal en las telecomunicaciones", en Derecho de las Telecomunicaciones, coord. CREMAdes, J., La Ley, Madrid, 1997, págs 757 y ss.; López LozANO, M. A., "La liberalización de las infraestructuras", en Derecho de las Telecomunicaciones, coord. Cremades, J., La Ley, Madrid, 1997, págs. 997 y ss.; CASTELLANO TREVILLA, J. L., "Servicio universal y los servicios obligatorios en la Ley General de Telecomunicaciones", en Curso de Derecho de las Telecomunicaciones, coord. Merino Merchán, J. F., y Pérez-UgenA, M., Dykinson, 2000, págs. 114-152; GonZÁLEZ QuinZÁ, A., "El servicio universal: el gran reto del nuevo derecho de las telecomunicaciones", Boletín del llustre Colegio de Abogados de Madrid, núm. 7, octubre 1997, págs. 83-108.

65 La liberalización en España parte de modificar la antigua Ley de Ordenación de las Telecomunicaciones 3/1987, por la Ley 32/1992 para la adecuación de la Ley de Ordenación de las Telecomunicaciones a las reglas dictadas por la Unión Europea en desarrollo del Libro Verde. Y la Posterior modificación a través de Decreto-ley 3/1996, de Liberalización de las Telecomunicaciones, aprobado como Ley 12/1997, de Liberalización de las Telecomunicaciones. La Ley 11/1998, General de Telecomunicaciones, por fin, considera las telecomunicaciones como servicios de interés general que se prestan en régimen de libre competencia, salvo ciertas excepciones relacionadas con la defensa y la protección civil. Con esta última ley se recoge un régimen regulador de telecomunicaciones basado en el artículo 38 
cio universal en la legislación sobre telecomunicaciones ${ }^{66}$. De esta forma, el operador dominante queda obligado a cumplir temporalmente con las obligaciones que impone el servicio universal. Estas obligaciones abarcan el derecho de conexión a red; de disponer de guia telefónica, de contar con oferta de telefónicos públicos y de acceso de los usuarios discapacitados. Con ello se pretenden cubrir dos objetivos. El primero trata de, en el respeto a principios de cohesión social y económica, evitar la falta de mínimos en la prestación de servicios de la que deriva la exclusión a parte de la población del uso de servicios de telecomunicaciones. De otra parte, atribuir esta obligación al operador dominante y eximir de tal carga a las nuevas empresas que entran a competir en telecomunicaciones se justifica por las necesidades de facilitar la entrada en el mercado a nuevos operadores, liberados temporalmente de obligaciones adicionales a la prestación del servicio que resulte rentable.

En el ámbito de Internet el principio de servicio universal ha encontrado su reflejo en la Declaración de derechos de Internet de la Comisión de Redes informáticas del Senado.

Esta Declaración aplica los principios de contenidos en los artículos 14 y 9.2 de la Constitución al ámbito de Internet. Señala, de una parte, el derecho de todos del acceso a la red sin discriminación, y de otra la obligación de los poderes públicos de lograr que la libertad y la igualdad de las personas en la red sea una realidad.

de la Constitución bajo un régimen de libre competencia. Respecto del proceso de liberalización de las telecomunicaciones existe una amplia bibliografía. Vid. Pérez Bustamante, R., "La Política de Telecomunicaciones en la Unión Europea", en Cur* so de Derecho de las Telecomunicaciones, coord. Merino Merchán, J. F, y PérezUgenA, M., Dykinson, 2000, págs. 287-296; del mismo autor, "Telecomunicaciones y Unión European, en Régimen Jurídico de las Telecomunicaciones, coord. Merino Merchán, J. F., y Pérez-Ugena, M., Tecnos, 1999, págs. 19-23; Cremades, J., Derecho de las Telecomunicaciones, La Ley, 1997; del mismo autor, La liberalización de las telecomunicaciones en un mundo globlal, Madrid, La Ley, 1998; sobre la liberalización del servicio de telefonía básica, como parte de proceso de liberalización de las telecomunicaciones, véase CREMADES, J., y SÁNCHEZ-PINTADO, "Telefonía básica: Entrada del segundo y tercer operador», en Régimen de las telecomunicaciones", coord. Merino Merchán, J. F., y Pérez-Ugena, M., Tecnos, 1999, págs. 191-211. También Davara Rodriguez, M. A., "La liberalización del mercado de las telecomunicaciones: una perspectiva desde la ética», en XII Encuentros sobre informática $y$ derecho 1998-1999, Aranzadi, 1999, págs. 129-137.

66 Ley General de Telecomunicaciones 11/1998 y Real Decreto 1736/1988 de desarrollo del Título III de la citada Ley. 
La aplicación del principio de igualdad en este sentido al ámbito de Internet no es más que una cara de la moneda. La otra se representa con las posibilidades de igualar a los desiguales que ofrece este medio. De manera que la utilización de nuevas tecnologías reduce las desigualdades entre áreas rurales y urbanas y permiten mayor capacidad de adaptación a disminuidos.

Entre los derechos sociales tenemos que referirnos a los derechos a la educación y al trabajo. En la sociedad de la información el derecho a la educación no se agota con los contenidos tradicionales. Integrar en la enseñanza los nuevos medios tecnológicos se ha convertido en una necesidad, al objeto de preparar la entrada en el mercado de trabajo, garantizar la igualdad de oportunidades y evitar la marginación social que pueda crearse en torno al analfabeto informático ${ }^{67}$.

La Unión Europea, consciente de la problemática expuesta, plantea la necesidad de renovar el sistema educativo de forma urgente, de manera especial para niños y jóvenes que se enfrentan a un mundo laboral distinto, así como de preparar al preparar al personal docente a estos efectos y crear mecanismos de educación continua que exige una renovación de competencias de manera permanente 68 .

En lo que al derecho del trabajo se refiere, partimos de las modificaciones fundamentales previsibles en este ámbito por la aplicación de las nuevas tecnologías, para señalar que fórmulas laborales más flexibles y con tendencia al autoempleo no deben desarrollarse en perjuicio del nivel de protección del trabajador. De manera especial, la actuación de los sindicatos deberá estar alerta a la hora de incidir sobre las políticas laborales y la adaptación de la legislación laboral a la evolución derivada de los nuevos soportes de comunicación ${ }^{69}$.

67 BuCETA FACORRO, L., Y MARTín GARCía, V., "Reflexiones sobre Educación y Tecnologías de la Información y la Comunicación", Sociedad y utopía, Revista de Ciencias Sociales, número extraordinario, 1999, págs. 71-77.

68 Ya en el informe Bangenman se hacía referencia a esta cuestión. vid en www.ispo.cec.be

69 Sobre la forma en que el papel de los sindicatos debe ser entendido en la actualidad vid. Jiménez de PARga y Pérez-Ugena, "Artículo 7", en los Comentarios a la Constitución española de 1978, dir. ALZAGA VILLAAMIL, O., tomo l, págs. 394-408. 


\section{B) Principios económicos y sociales}

En el ámbito de los principios económicos y sociales destacamos, conscientes de no agotar las posibilidades, la protección de personas con discapacidad, los derechos de los usuarios y la salud.

La relación entre nuevas tecnologias y discapacidad puede articularse en torno a dos criterios; dificultades de acceso y posibilidades que ofrecen los medios.

Las dificultades de acceso se producen en gran número de casos debido a la aplicación de formatos complejos que necesita sistemas de adaptación que naturalmente precisan un tiempo de desarrollo ${ }^{70}$. La Organización Nacional de Ciegos de España está desarrollando una labor de concienciación social en este sentido por entender que los servicios a través de la Red son cada vez más necesarios para la vida diaria de los ciudadanos ${ }^{71}$. Los nuevos medios, de otra parte, producen evidentes beneficios en cuanto a las posibilidades de empleo de minusválidos ${ }^{72}$.

Los usuarios, al hacer uso de las nuevas tecnologías, desarroIlan sus actividades en un mundo global que conlleva un nuevo contexto con el que no están familiarizados y en el que pretenden ejercer sus derechos. La entrada en ese nuevo contexto conlleva ciertos riesgos que exigen garantías de protección de sus derechos. Tales garantías exigen, al menos, que el usuario esté informado, que no exista discriminación en el acceso a productos y servicios, que se creen medios de filtrado del contenido de los sistemas de comunicación personalizado, que se lleven a cabo políticas de promoción de la diversidad en lenguas y culturas, que los intereses económicos se protejan, luchan-

70 VANDERHEIDEN, G. C., "Accesibilidad a Internet: aspectos fundamentales y avanzados del acceso multimodal a la red actual y futuran, en Novatica 136, recoge una visión general sobre el problema de accesibilidad para personas con discapacidad, si bien, parte de que la mayoría de las características que hacen la web más accesible para personas con discapacidad también la hacen más accesible para personas sin discapacidad. Puede consultarse en www.ati.es/publicaciones/novatica/1998/136/grevan.htm/ (Revista de ATI, Asociación de Técnicos de Informática).

71 Puede verse amplia información al respecto en www.once.es

72 Diaz, E.; Montero, A.; Mora, A.; Pablos, C., y Segura, M. J. (Grupo TeCNOR CESSJ "Ramón Carande", Universidad Rey Juan Carlos"). "La integración del discapacitado en el mercado laboral a través de las nuevas formas organizativas de trabajo", Studia Carande, vol. II, 1999, págs. 97-120. El resultado de encuestas del Instituto Nacional de Estadística en este sentido puede verse en www.ine.es 
do frente a prácticas comerciales engañosas y desleales, que se desarrollen formulas a través de las cuales el usuario pueda exigir responsabilidad, que incluyan la posibilidad de aplicar los derechos que le otorga su país de residencia así como que tenga facilidad para acceder a la jurisdicción, que se establezcan medios de protección de la salud y que el consumidor cuente con representantes de sus intereses en los órganos de control y vigilancia ${ }^{73}$.

Por último, la aplicación de nuevas tecnologías tiene un campo muy amplio en el ámbito de la salud, de forma especial en la actualidad $y$ ante el descubrimiento del genoma humano. El estudio de la relación entre el derecho y la salud desemboca en una temática, desde nuestro punto de vista muy interesante, cual es la bio-genética. Este tema, como decimos, guarda una estrecha conexión con la materia que nos ocupa.

Si la cibernética es la ciencia que estudia la relación hombre máquina y ofrece métodos para el estudio de sistemas complejos, partiendo de la distinción entre sistemas vivientes y no vivientes, es claro que su utilización es común a la biología y a la tecnología ${ }^{74}$.

El desarrollo tecnológico propio de la sociedad de la información permite procesar la información necesaria para poner los cimientos de la bio-tecnología por cuanto capacita para descodificar información contenida en los organismos vivos. Tenemos, pues, que concluir con la lógica de que las revoluciones biológica y electrónica converjan desde campos distintos en la sociedad de la información.

Finaliza así nuestro trabajo, con el que hemos tratado de señalar algunos de los problemas que supone el desarrollo tecnológico para los derechos en el ámbito de la sociedad de la información.

73 Al respecto vid. Merino MerCháN, J. F., «Derechos de los usuarios en materia de telecomunicaciones", en Curso de Derecho de las Telecomunicaciones, coord. Merino Merchán, J. F., y Pérez-Ugena, M., Dykinson 2000, págs. 39-69.

74 La cibernética fue definida por el matemático Wiener como la ciencia del control y la comunicación en el animal y en la máquina. Se trataba de crear un título común para los problemas que se encuentran tanto en la fisiología como en la tecnología informática. Se incluyen dentro de esta ciencia que es la cibernética, la mente humana, el cuerpo humano y el mundo de las máquinas automáticas en una relación que le viene dada por la comunicación y el control. Al respecto vid. WIENER, N., Cibernética, control y comunicación en animales y máquinas, Tusquets, Barcelona, 1985. Vid. También Ross AshBy, Introducción a la Cibernética, Ediapsa, Méjico, 1977; CONTRERAS, F., El cibermundo, dialéctica del discurso informático, Alfar, Sevilla, 1988. 